\title{
Immunogenetics of multiple sclerosis: more questions than answers
}

\author{
Imunogenética da esclerose múltipla: mais questões do que respostas
}

Tarso Adoni ${ }^{1}$

${ }^{1}$ Hospital Sírio-Libanês, São Paulo SP, Brasil.

\section{Correspondence:}

Tarso Adoni; Rua Dona Adma

Jafet, 74 / conj. 121;01308-050

São Paulo SP, Brasil;

E-mail:tarso@dfvneuro.com.br

Conflict of interest:

There is no conflict of interest to declare.

Received 14 July 2016

Accepted 21 July 2016

\section{(c) BY}

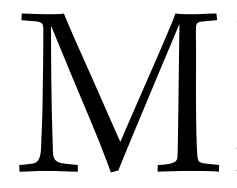

ultiple sclerosis (MS) is an immune-mediated chronic disease that affects mainly young people and usually evolves with progressive accumulation of disability in most patients over many years to decades ${ }^{1}$. There is a known latitudinal gradient of prevalence of MS: the higher the latitude, the farther away from the equator, the greater the number of affected people ${ }^{2}$. The existence of a latitude association for the development of MS brings with itself the influence of low sun exposure as a risk factor ${ }^{3}$. However, there are regions or ethnic groups in which, regardless of the latitude, people can present a greater or lesser risk of developing MS. Sardinians are well known exceptions as they present a much higher incidence of MS compared to the rest of Italy and even with other Mediterranean populations, which could be explained by genetic aspects ${ }^{4}$. On the other hand, regions in the far north of Norway have low incidences of MS compared to countries in the same latitude, pointing toward the influence of environmental factors more than genetic predisposition ${ }^{5}$.

MS is a complex disease which is not triggered by a single factor but by the combination of genetic and environmental factors. Among the latter, in addition to the increased risk of developing MS by low levels of vitamin D (hence the relationship with sun exposure), obesity, smoking, EBV infection and excessive sodium intake in the diet are factors involved ${ }^{6}$. We must also mention the recent but not definitive studies of the relationship between gut microbiome and multiple sclerosis?

Regarding genetic factors, the question is not simple either and there is no single gene involved. From the scientific point of view, there are two possible types of genetic approach. The first and oldest of them is the study of the HLA system, which has established risk haplotypes in different populations with the knowledge already well established nowadays at an odds ratio of around 3 to develop MS in individuals with the allele HLA -DRB1*15: 01. However, the presence of this allele is neither sufficient nor necessary for the onset of MS because subjects without the allele can also develop the disease as well as many individuals carrying the risk allele who will never develop the disease. Another more recent approach is to study genes outside the HLA system identifying single-nucleotide polymorphisms (SNPs) through genome-wide association. So far, at least 57 SNPs that increase the risk of developing MS have been identified ${ }^{8}$.

In this issue of Arquivos de Neuropsiquiatria, Werneck et al. ${ }^{9}$ chose to study the relationship between HLA alleles and the susceptibility to the development of MS in a population in Southern Brazil. The authors found a lower frequency than that described in European populations and even in Southeastern Brazil. The merit of the work was the use of highresolution technique for detection of HLA alleles. However, there are some problems which have been pointed out by the authors. First, the small number of cases included, which makes any consideration about the real impact of miscegenation in the South of Brazil in the obtained results not strong enough. Secondly, the difficulty in comparing the results of Werneck et al. with those obtained by low-resolution techniques to detect HLA alleles in other populations. Finally, it would be interesting if data about prognosis and HLA alleles could have been analyzed by the authors, perhaps in a future publication. There are data showing worse prognosis of MS in African American patients according to certain HLA 
alleles ${ }^{10}$. Since the authors have Expanded Disability Status Scale (EDSS) available and included in their research mostly Caucasians, it would be very interesting to compare these results with the North American publication.

In summary, Werneck et al. ${ }^{9}$ show new immunogenetic data in MS patients in Southern Brazil, which deserve more attention. As also mentioned by the authors, there is the issue not fully resolved regarding the influence of epigenetic mechanisms in the development of MS and other autoimmune diseases. The best example of the influence of epigenetic mechanisms is the concordance rate among identical twins, about $40 \%{ }^{11}$. Epigenetic did away with our claim to "know the genome and then know all". The fact is that epigenetics is here, for good and evil.

\section{References}

1. Hauser SL, Goodin DS. Multiple Sclerosis and other demyelinating diseases. In: Longo DL, Fauci AS, Kasper DL, Hauser SL, Jameson JL, Loscalzo J, editors. Harrison's principle of internal medicine. 18th ed. New York: McGraw Hill; 2012. p. 3395-409.

2. Simpson S Jr, Blizzard L, Otahal P, Mei I, Taylor B. Latitude is significantly associated with the prevalence of multiple sclerosis: a meta-analysis. J Neurol Neurosurg Psychiatry. 2011;82(10):1132-41. doi:10.1136/jnnp.2011.240432

3. Mei IA, Ponsonby AL, Dwyer T, Blizzard L, Simmons R, Taylor BV et al. Past exposure to sun, skin phenotype, and risk of multiple sclerosis: Case-control study. BMJ. 2003;327(7410):316. doi:10.1136/bmj.327.7410.316

4. Ristori G, Cannoni S, Stazi MA, Vanacore N, Cotichini R, Alfò M et al. Multiple sclerosis in twins from continental Italy and Sardinia: a nationwide study. Ann Neurol. 2006;59(1):27-34. doi:10.1002/ana.20683

5. Ebers GC. Environmental factors and multiple sclerosis. Lancet Neurol. 2008;7(3):268-77. doi:10.1016/S1474-4422(08)70042-5

6. Coyle PK. Symptom management and lifestyle modifications in multiple sclerosis. Continuum (Minneap Minn). 2016;22(3
Multiple Sclerosis and Other Demyelinating Diseases):815-36. doi:10.1212/CON.0000000000000325

7. Jangi S, Gandhi R, Cox LM, Li N, Glehn F, Yan R et al. Alterations of the human gut microbiome in multiple sclerosis. Nat Commun. 2016;7:12015. doi:10.1038/ncomms12015

8. Sawcer S, Franklin RJM, Ban M. Multiple sclerosis genetics. Lancet Neurol. 2014;13(7):700-9. doi:10.1016/S1474-4422(14)70041-9

9. Werneck LC, Lorenzoni PJ, Arndt RC, Kay CSK, Scola RH. The immunogenetics of multiple sclerosis. The frequency of HLA-alleles class 1 and 2 is lower in Southern Brazil than in the European population. Arq Neuropsiquiatr. 2016;74(8):607-16. doi: 10.1590/0004-282X20160100

10. Cree BA, Reich DE, Khan O, De Jager PL, Nakashima I, Takahashi $T$ et al. Modification of multiple sclerosis phenotypes by African ancestry at HLA. Arch Neurol. 2009;66(2):226-33. doi:10.1001/archneurol.2008.541

11. Hansen T, Skytthe A, Stenager E, Petersen HC, Kyvik KO, Brønnum-Hansen $\mathrm{H}$ et al. Risk for multiple sclerosis in dizygotic and monozygotic twins. Mult Scler. 2005;11(5):500-3. doi:10.1191/1352458505ms1202oa 